\title{
EVOLUÇÃO MAGMÁTICA DOS GRANITÓIDES PROTEROZÓICOS DO SETOR SETENTRIONAL DA PROVÍNCIA ESTRUTURAL MANTIQUEIRA, MINAS GERAIS, ESPÍRITO SANTO, BRASIL
}

\author{
Essaïd Bilal ${ }^{1}$, Adolf Heinrich Horn ${ }^{2}$, Hermínio Arias Nalini Jr. ${ }^{3}$, \\ José Marques Correia-Neves ${ }^{4}$, Fernando Machado de Mello ${ }^{5}$
}

\begin{abstract}
Neoproterozoic granitoid suites in southeastern Brazil are closely related to the different tectonic phases within the Brasiliano tectonic-thermal Event. Petrography, geochemistry and structural features allow to separate these rocks into pre-, syn-, late and post-tectonic granitoids.

The whole emplacement process lasted about $100 \mathrm{Ma}$ : from $595 \mathrm{Ma}$ for the pre-tectonic granitoids, to near $490 \mathrm{Ma}$ for the post-tectonic ones. During this interval a 45 Ma magmatic quiet period (from 582 to 537 Ma) can also be characterized.

Detailed field observations and mapping, coupled with petrological and geochemical and observations, indicate the important role of the Archean and Paleoproterozoic crust in the genesis of these granitoids, showing even evidences of important mantle interactions.

Keywords: Mantiqueira Structural Province; Pre-tectonic Granitoids; Syn-tectonic Granitoids; Post-tectonic Granitoids; Geochemical signatures; Magmatic and Tectonic Relationship; Minas Gerais-Brazil.
\end{abstract}

\section{INTRODUÇÃO}

Sínteses sobre magmatismo e geotectônica do setor setentrional da Província Mantiqueira foram apresentadas por Campos Neto \& Figueiredo (1995), Wiedemann (1993), Ebert et al. (1996), Pedrosa-Soares et al. (1999) e Pedrosa-Soares \& WiedemannLeonardos (2000).

A finalidade deste trabalho é apresentar uma síntese do mesmo tipo para a parte centro-norte da Província Estrutural Mantiqueira, na região delimitada pelos paralelos $17^{\circ} 00^{\prime}$ e $19^{\circ} 00^{\prime}$.

Muitos trabalhos de detalhe, já desenvolvidos sobre granitóides e rochas encaixantes da região, envolvendo estudos bibliográficos, cartográficos, petrográficos, geoquímicos e geocronológicos, permitem-nos propor uma interpretação para o posicionamento das intrusões granitóides e discutir a sua importância na evolução orogênica na parte Centro Norte da Província Mantiqueira.

\section{ENQUADRAMENTO GEOLÓGICO}

A parte Centro Norte da Província Estrutural Mantiqueira (PEM) está localizada na região sudeste do Brasil, na borda oriental do Craton do São Francisco abrangendo a porção centro oriental do Estado de Minas Gerais e o NW do Estado do Espírito Santo. Esse setor é aproximadamente delimitado pelos paralelos $17^{\circ} 00^{\prime}$ e $21^{\circ} 00$ 'S. A PEM é representada por faixas móveis Neoproterozóicas associadas ao Evento Brasiliano (600 - 450Ma). Eles bordejam o bloco cratônico do São
Francisco. Estas faixas móveis resultaram do retrabalhamento de formações eoproterozóicas (rochas com alto e baixo grau de metamorfismo dos Complexos Piedade, Paraíba do Sul e Pocrane) e das sequiências supracrustais do fim do Proterozóico (Grupo Rio Doce). Durante estas fases termo-tectônicas do Evento Brasiliano originaram-se as diversas gerações de granitóides e de pegmatitos (Correia Neves et al. 1986; Bilal et al. 1998, 2000a, 2000b; Morteani et al. 2000). Vários pegmatitos, especialmente os pegmatitos com elementos raros, morganita e turmalinas coradas, estão normalmente alojados nos Xistos São Tomé segundo os planos de foliação (figura 1).

A evolução regional foi condicionada pelas zonas de cisalhamento Governador Valadares-Guaçuí e de Vitória. Caracterizam-se duas fases principais de deformação, desenvolvidas sob condições de fácies anfibolítica (Nalini 1997; Bilal et al. 2000b), uma ( $\left.D_{1}\right)$ anterior e outra $\left(\mathrm{D}_{2}\right)$ posterior ao posicionamento dos granitóides.

A deformação $\mathrm{D}_{1}, \mathrm{~N} 10-30^{\circ}$ de médio a alto grau, foi responsável pela foliação penetrativa (estado sólido) e pela lineação mineral observada quer nas rochas encaixantes, quer nos granitóides. Afetou os granitos Pré-tectônicos e controlou a foliação dos granitóides Sín-tectônicos. Esta foliação, associada as lineações oblíquas e aos estudos cinemáticos sugere que as zonas de cisalhamento subverticais foram importantes durante o posicionamento dos granitóides (Nalini 1997; Bilal et al. 2000a).

A deformação $\mathrm{D}_{2}$, caracterizada pela clivagem de crenulação, boudinagem e falhamento normal, associou- 
se a uma fase extensiva, contemporânea do posicionamento dos granitóides Pós-tectônicos.

Dados recentes de geocronologia (U-Pb: Söllner et al. 1991; Machado et al. 1996 e Sm-Nd: Fischel et al. 1998), demonstram a existência de dois eventos termotectônicos nesta região, ocorridos entre 590-565Ma e 535-520Ma.

\section{MAGMATISMO}

\section{Plutonismo Pré-Tectônico}

A suíte dos granitóides Galiléia, com $595 \mathrm{Ma}$ (Nalini 1997), corresponde a um corpo maciço extenso e multidiapírico (Figura 1). Esta suíte, predominantemente granodiorítica, com enclaves microgranulares, apresenta subordinadamente tonalitos, granitos e microgranitos (Nalini 1997; Bilal et al. 2000a; Nalini et al. 2000). A mineralogia essencial destes granitóides é integrada por quartzo, plagioclásio, feldspato potássico, biotita, anfibólio e granada e a mineralogia acessória apresenta alanita, clinozoisita, titanita, apatita e zircão. Nos enclaves encontra-se a mesma associação mineralógica, porém, os minerais máficos existem em maior proporção.

As granadas ricas são de composição grossulária $\left(\mathrm{Al}_{40-64} \mathrm{Gr}_{20-42} \mathrm{Sp}_{7-15} \mathrm{Py}_{3-9}\right)$ e os plagioclásios apresentam um teor anortítico variando entre $\left(\mathrm{An}_{70-80}\right)$ até $\left(\mathrm{An}_{26}\right)$. No diagrama de Nachit et al. (1985; Figura 2) as biotitas projetam-se no campo cálcio-alcalino. Os anfibólios exibem uma composição de hornblenda tchermackítica e hornblenda ferrífera. Estes granitóides são caracterizados por duas populações de zircões (Nalini et al. 1997). A primeira população é típica de uma temperatura elevada (cerca de $850^{\circ} \mathrm{C}$ ) e de condições de cristalização em ambiente seco. Ela é característica de granitos cálcio-alcalinos (Pupin 1980). A segunda população, diferenciada por um amplo índice alcalino (IA) e baixa temperatura de cristalização (cerca de $650^{\circ} \mathrm{C}$ ) é típica da contaminação crustal ou de processos de mistura magmática.

Usando o teor em Al nas hornblendas estudadas, que é função das condições pressão de sua gênese (Schmidt 1992), estimaram-se valores variando entre 8 e $10 \mathrm{~Kb}$ que são necessárias para explicar a presença nestes granitóides da granada rica em grossulária.

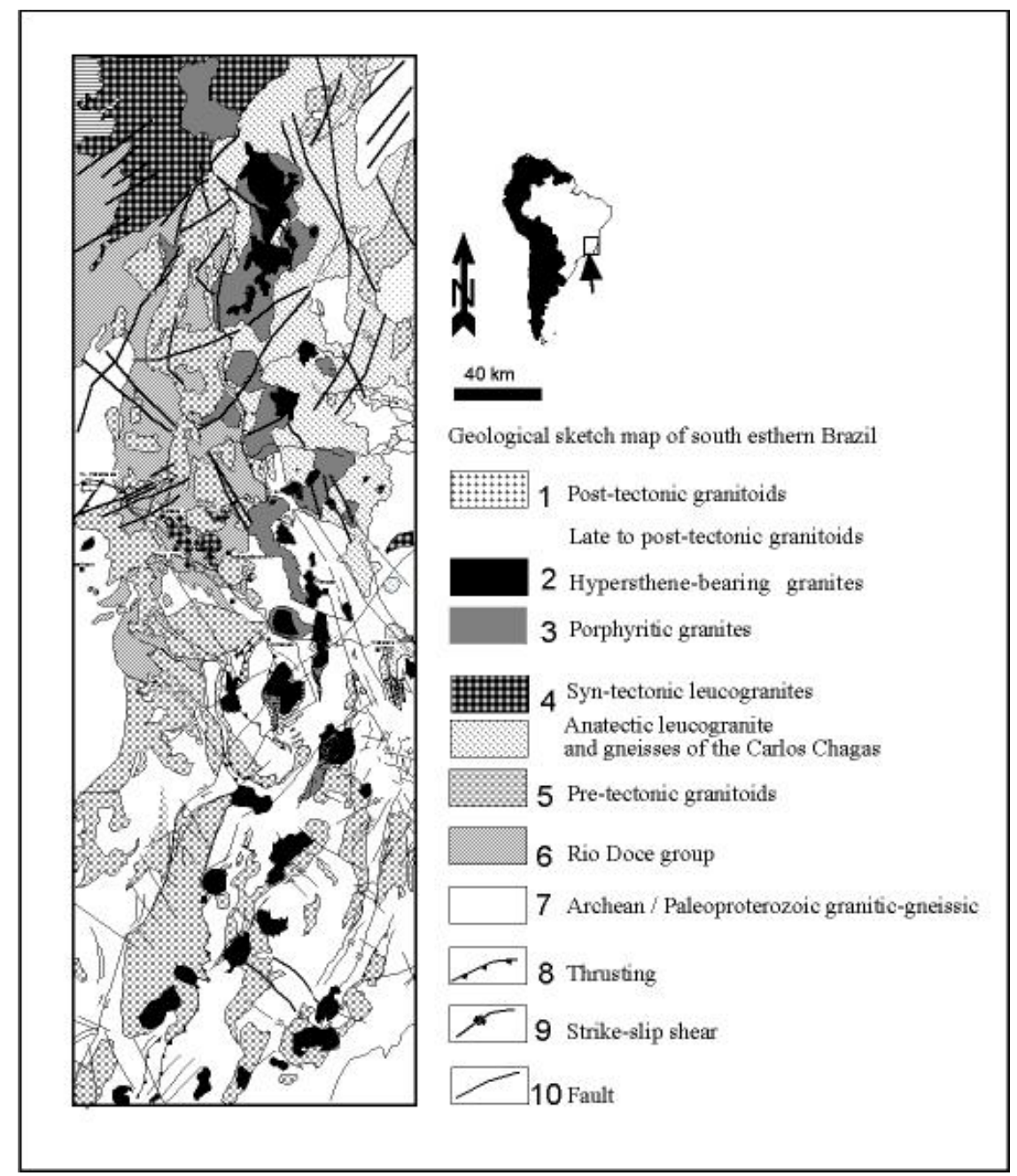

Figura 1: Mapa geológico do Sudeste Brasileiro com os suítes magmáticos. Dados compilados deste trabalho e Pinto (1997).

Figure 1: Geological sketch map of south-eastern Brazil with the magmatic suites. Data compilation from this work and Pinto (1997). 


\section{Plutonismo Sin-tectônico}

Na porção mais a leste do estado de Minas Gerais (figura 1), os granitóides Sin-tectônicos são heterogêneos com corpos isolados do migmatitos e do leucossoma. A presença de sillimanita, de cordierita, de granada indicam o caracter peraluminoso destes granitóides. Na porção mais a oeste predominam os granitóides da suíte Urucum, com idade U-Pb de 582 Ma. (Nalini et al. 1997). O caráter Sín-tectônico da Suíte Urucum é evidenciado pela foliação magmática paralela ao plano axial da foliação regional $\left(\mathrm{N} 10^{\circ}-30^{\circ} \mathrm{W} / 55^{\circ}\right.$ $\left.75^{\circ} \mathrm{SW}\right)$ medida nas rochas encaixantes. Os granitóides desta suíte são intrusivos quer nos xistos São Tomé, os quais aparecem como xenólitos nos granitóides da Suíte Urucum, quer nos granitóides Pré-tectônicos. Os tipos petrográficos que se caracterizam nos granitóides Síntectônicos são: granitos com megacristais de feldspato alcalino que marcam a foliação e a lineação; granitos de grã fina a média; granitos turmaliníferos; aplopegmatitos e pegmatitos. A mineralogia essencial dos granitóides Sín-tectônicos é constituída por quartzo, microclina, plagioclásio (oligoclásio - andesina), biotita e moscovita, sendo a mineralogia acessória formada por granada, sillimanita, cordierita, monazita, apatita, turmalina e zircão.

Os valores da razão $\mathrm{Al} / \mathrm{Mg}$ das biotitas destes leucogranitos Sín-tectônicos são típicos de granitos aluminopotássicos (Figura 2) de acordo com a classificação de Nachit et al. (1986). As moscovitas, cuja composição é controlada pela substituição fengítica.

A granada $\left(\mathrm{Al}_{60-65} \mathrm{Sp}_{27-29} \mathrm{Gr}_{2-10} \mathrm{Py}_{3-4}\right)$ dos leucogranitos é mais rica em almandina e espessartita e mais pobre em grossulária do que a encontrada nos granitos Pré-tectônicos do suíte Galiléia. Os tipos de zircões destes granitóides são indicadores de granitos crustais. As temperaturas de cristalização os granitos Sín-tectônicos variando entre 500 e $750^{\circ} \mathrm{C}$ e pressões oscilando entre 4 e $5 \mathrm{~Kb}$.

\section{Plutonismo Tardi- a Pós-tectônico}

Os Complexos intrusivos anelares de Aimorés, Ibituba-Itapina, Varzea Alegre, Garrafão e Padre Paraíso, com idades variando entre $520 \mathrm{Ma}$ e $537 \mathrm{Ma}$, estão situados (Figura 1) no Estado do Espírito Santo e no leste do Estado de Minas Gerais. Os corpos intrusivos, posicionados dentro dos Complexos Juiz de Fora e Paraíba do Sul que têm idades variando desde o Arqueano ao Proterozóico (Horn et al. 1996, 1998; Bilal et al. 2000a). Estes complexos intrusivos, com estrutura \pm anelar, são formados geralmente por três fácies petrográficas distintos descritos a seguir por ordem de sua intrusão:

— um diorito de grão fino ocupando geralmente o centro do complexo intrusivo anelar

- uma capa aparecendo como anel de granito hiperstênico e finalmente

- um corpo lateral de composição graníticagranodiorítica.

O contato entre estas fácies petrográficas e as rochas

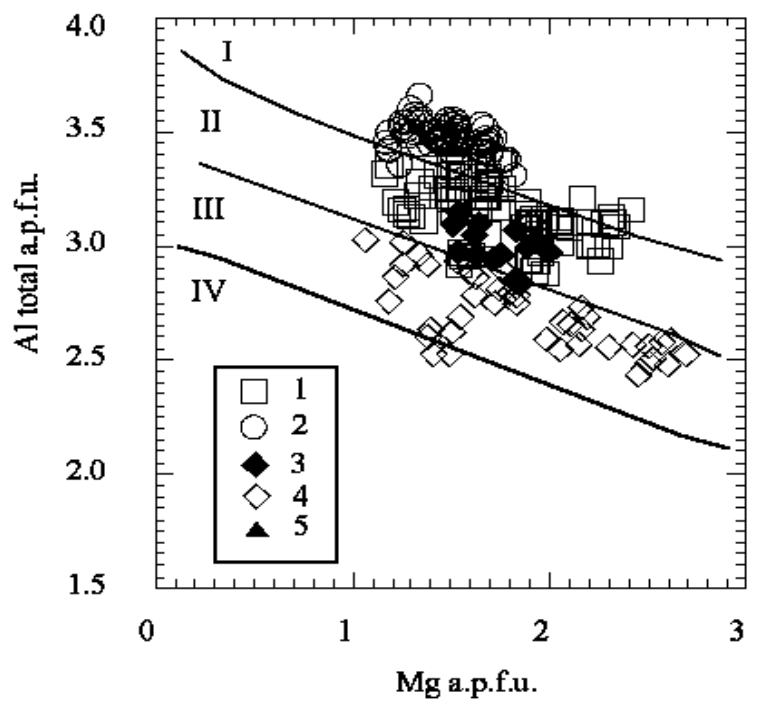

Figura 2: Al-Mg (p.f. u.) - Diagrama de discriminação (Nachit 1986). Comparação da composição das biotitas dos suítes neoproterozoicos

da região do Rio Doce: 1. Granitóides Pré-

tectônicos; 2. Leucogranitos Sín-tectônicos; 3.

Granitos porfíricos; 4. Granitos com híperstênio; 5. Granitóides Pós-tectônicos.

Figure 2: Al versus $\mathrm{Mg}$ (p.f. u.) discrimination diagram (Nachit 1986). Comparison of the biotite compositions of Neoproterozoic granitoids suites of Rio Doce Region. 1: Pre-tectonic granitoids; 2: sintectonic leucogranites; 3: porphyritic granites; 4 :

hypersthene bearing granite; 5: post-tectonic granitoids.

encaixantes é geralmente nítido e quase vertical. Os contatos intraplutônicos, no Complexo de Aimorés como no Complexo Ibituba-Itapina, são caracterizados por claras manifestações de "mixing" e "mingling" magmáticas indicando um posicionamento sincrônico destes granitóides e que a diferenciação magmática “in situ" desempenhou um papel importante na gênese das suítes destes granitóides que contém muitos enclaves magmáticos microgranulares e xenólitos das rochas metamórficas encaixantes. Nos contatos as texturas magmáticas estão geralmente preservadas ainda que apresentem, sobretudo nos contatos com as rochas metamórficas, deformações desenvolvidas no estado sólido e relacionadas com a dinâmica da intrusão.

As biotitas dos granitóides hiperstênicos, que correspondem à fácies mais importante, ficam representadas no campo subalcalino (Figura 2) do diagrama Mg-Al de Nachit et al. (1986).

A pressão no posicionamento destes plútons foi estimada usando o geo-barómetro de Schmidt (1992), que relaciona a pressão com o teor em $\mathrm{Al}$ do anfibólio. Os valores encontrados foram 6 a $7 \mathrm{Kbar}$. Com base na composição dos ortopiroxênios e dos clinopiroxênios dos dioritos e dos granitos hiperstênicos, usando o geotermômetro de Wells (1977) obtiveram-se temperaturas de cristalização de $870^{\circ} \mathrm{C}$ e $750^{\circ} \mathrm{C}$, respectivamente. 
Todas as fácies destes complexos intrusivo-anelares foram cortadas por rochas de granitóides porfiríticos essencialmente constituída por granito de grão grosso, granodiorito e granito de grão fino. Esta última suíte, correspondendo a cerca de $15 \%$ do volume dos tipos petrográficos existentes nos complexos intrusivos anelares.

As composição das biotitas dos granitóides porfiríticos plotam entre os campos dos granitos cálcioalcalinos e dos granitos subalcalinos (Figura 2). Usando vários métodos termobarométricos, foram estimadas a temperatura $\left(760^{\circ} \mathrm{C}\right)$ e a pressão (6Kbar) de cristalização destes granitóides porfiríticos.

\section{Plútons Pós-tectônicos}

O magmatismo Pós-tectônico é representado por uma grande distribuição de diques sieno-graníticos, mas alguns plútons mais extensos são conhecidos como p. ex. os complexos de Ibituruna, Aracé e Garrafão (figura 1). Todos são constituídos por sienitos quartzíferos e sienogranitos a que se associam secundariamente granitos e gabros. O melhor estudado é o complexo sienítico do Ibituruna, com 500Ma (U/Pb em titanita) e que está situado, próximo a Governador Valadares na margem direita do Rio Doce, em embasamento Eoproterozóico. O complexo é constituído predominantemente por sienito e sienito quartzífero (Bilal \& Correia Neves 1997; Bilal et al. 1998, 2000a). O granito alcalino aparece, sobretudo na borda oeste do maciço, sob a forma de diques cortando o sienito. Ocorre ainda sob a forma de diques anelares, bem desenvolvidos na margem SW do complexo. Um aspecto característico do sienito é a presença freqüente de enclaves máficos e de xenocristais de composição máfica a ultramáfica.

A composição química dos clinopiroxênios sieníticos e graníticos oscila entre $\mathrm{Di}_{43} \mathrm{He}_{36} \mathrm{Ac}_{21} \mathrm{e} \mathrm{Di}_{26} \mathrm{He}_{34} \mathrm{Ac}_{40}$. Os anfibólios pertencem à série hastingsita-hornblenda $\mathrm{e}$ cristalizam sob pressões de 4 a 5 Kbars e para baixa

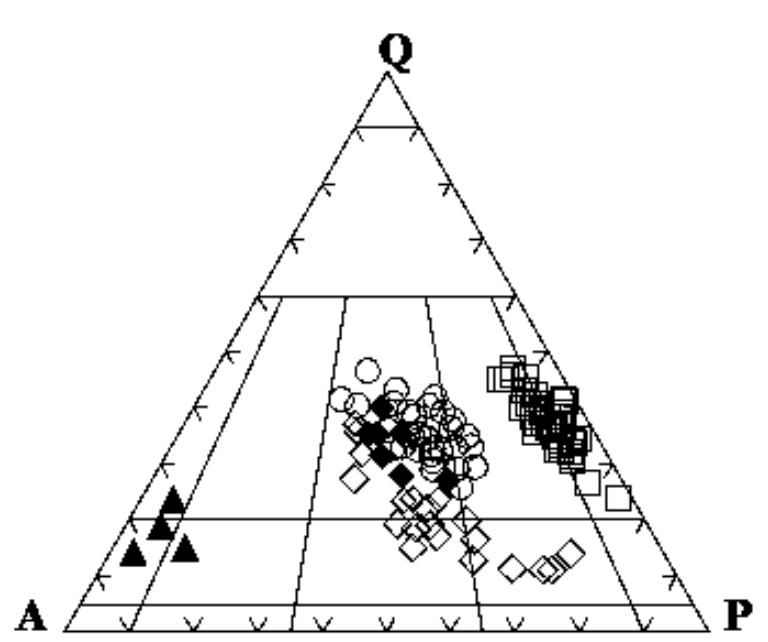

Figura 3: Diagrama modal QAP (segundo Bowden et al. 1984) com os suítes magmáticos da região do Rio Doce. Símbolos como na figura 1. Figure 3: QAP modal diagram (after Bowden et al. 1984) with de magmatic suites of the Rio Doce region. Symbols like in figure 1.

fugacidade do Oxigênio ( $\mathrm{fO}_{2}$ ). Usando o geotermômetro de Blundy \& Holland (1990), para uma pressão de carga de $4 \mathrm{Kbars}$, estima-se uma temperatura de $920^{\circ}-1000^{\circ} \mathrm{C}$ para a segregação dos anfibólios.

\section{CARACTERÍSTICAS GEOQUÍMICAS}

Para as suítes (Pré- a Pós tectônico) granitóides do Neoproterozóico da região SE definem claramente quatro campos distintos no diagrama QAP de Streckeisen (Figura 3): (1) cálcio-alcalina; (2) dos granitos crustais; (3) monzonítica subalcalina e (4) alcalina segundo Bowden et al. (1984). Elas encontram-se obviamente delineadas também no diagrama $R_{1}-R_{2}$ de De La Roche et al. (1980) como é mostrado na figura 4.

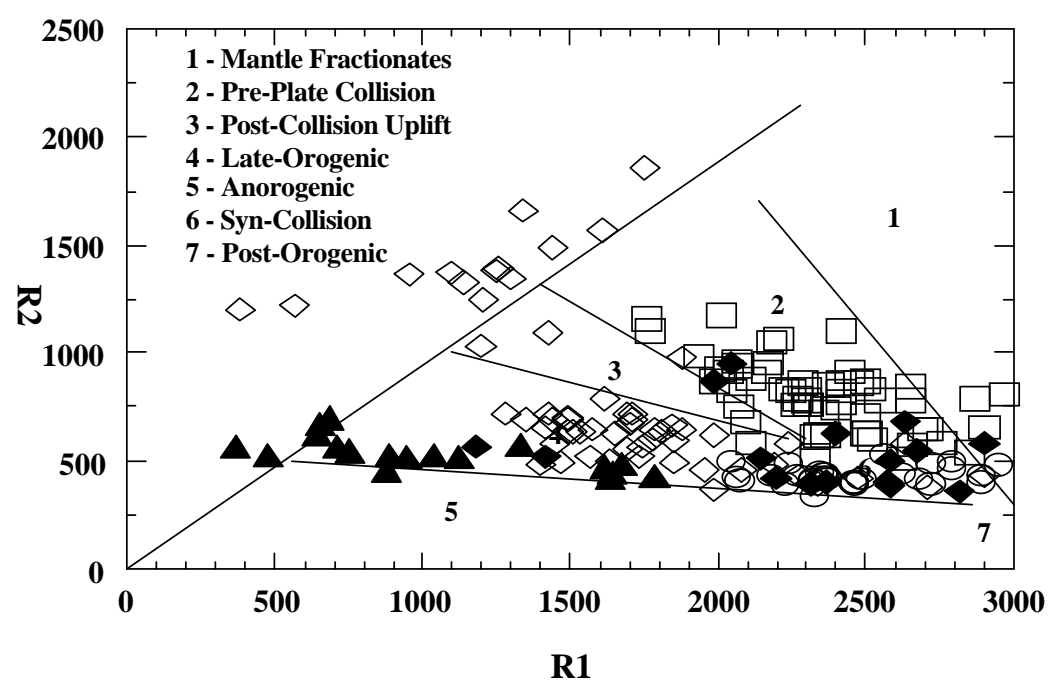

Figura 4: Os magmatitos da região Rio Doce no diagrama de De La Roche (1980). As delimitações são de Bowden (1984). Símbolos como na figura 1.

Figure 4: The magmatites of the Rio Doce region in the de la Roche diagram (1980). The boundaries are from Bowden (1984). Symbols see figure 1. 
Exceto nos granitóides Sín-tectônicos, o índice de saturação em alumína (ASI) aumenta com o índice de diferenciação, ou seja, com a diminuição do teor em $\mathrm{MgO}$ (Figura 5). Esta evolução inicialmente é muito acentuada, porém, torna-se mais lenta com o inicio da cristalização da biotita quando o valor de ASI é igual a 1. Este comportamento dos granitóides Sín-tectônicos pode estar relacionado com a cristalização de turmalina rica em $\mathrm{Al}$, de granada, sillimanita e de cordierita que rebaixam o valor de ASI no líquido magmático residual. Nos granitóides das outros suítes (Pré-, Tardi e Póstectônico) a cristalização do piroxênio e do anfibólio, pobres em Al, faz com que o valor do ASI aumente. As rochas granitóides destes diferentes suítes magmáticas atingem a saturação em $\mathrm{Al}$ ( $\mathrm{ASI}=1$ ) para teores de $\mathrm{MgO}$ específicos para cada uma delas, nomeadamente: $0,7 \%$ $\mathrm{MgO}$ no caso dos granitóides (Suíte) Pós-tectônicos; 2,0\% MgO para os granitóides (Suíte) Pré-tectônicos e 3,2\% MgO para os granitóides (Suíte) Tardi-tectônicos ricos em $\mathrm{Mg}$. Deve se destacar que os granitóides Pré- tectônicos, os mais pobres em $\mathrm{Mg}$, são saturados em Al, enquanto que os granitóides Tardi-tectônicos com os teores mais elevados em $\mathrm{MgO}$ são igualmente muito ricos em Al. Isto pode significar que a fusão, a partir da qual cristalizaram os granitóides Tardi-tectônicos, se originou de uma mistura de magmas: um gerado na crosta por fusão parcial de um protólito metassedimentar e um outro, muito rico em $\mathrm{MgO}$, de origem mantélica.

Nos granitóides Pós-tectônicos a razão $\mathrm{MgO} / \mathrm{TiO}_{2}$ aproxima-se de 1. Considerando um modelo de fusão parcial, o valor da razão $\mathrm{MgO} / \mathrm{TiO}_{2}$ dependerá principalmente da composição inicial do magma. Nos granitos do tipo $\mathrm{S}$ de origem crustal (Suíte dos granitóides Sín-tectônicos), bem como na própria crosta, o valor da razão $\mathrm{MgO} / \mathrm{TiO}_{2}$ é próximo de 3. Em tais rochas a granada e a turmalina, que normalmente ocorrem, desempenham um papel importante na partição do $\mathrm{Mg}$ e do $\mathrm{Fe}^{++}$. Nos granitóides que estamos considerando a biotita é sempre mais rica em Fe do que a turmalina (figura 5).
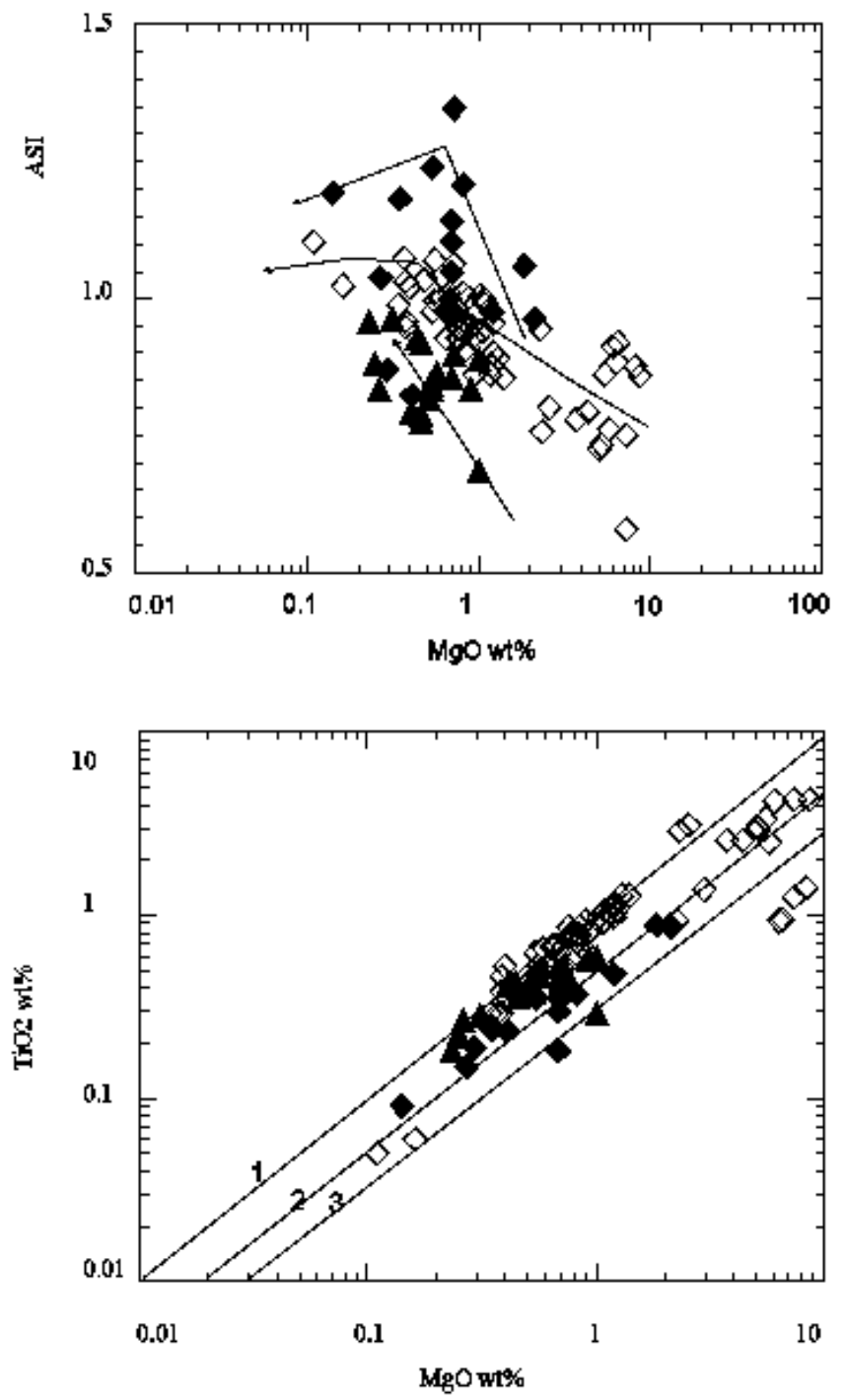

Figura 5: Asi-MgO e TiO_-MgO Diagramas para os suítes da região Rio Doce. Os símbolos são os mesmos do que na figura 1.

Figure 5: Asi-MgO and $\mathrm{TiO}_{2}-\mathrm{MgO}$ diagrams for the rock suites of the Rio Doce region. The symbols are the same as in figure 1. 
Os granitóides (Suítes) Pré- e Tardi-tectônicos da região estudado são caracterizados por valores muito altos da razão $\mathrm{MgO} / \mathrm{TiO}_{2}$ (valores entre 2 e 3) o que parece revelar uma mistura de magmas crustais e mantélicos. Esta observação está confirmada por estudos petrológicos e pela geoquímica isotópica (Nalini, 1997).

As Suítes dos granitóides Tardi- e Pós-tectônicos são caracterizados por teores em $\mathrm{K}_{2} \mathrm{O}$ (Figura 6) e por valores da razão $\mathrm{FeO}^{*} /(\mathrm{FeO}+\mathrm{MgO})$, muito mais altos do que os que caracterizam as suítes dos granitóides Pré- e sintectônicos. Estes granitóides podem ser comparados ao suíte dos granitóides ricos em $\mathrm{Fe}$ e $\mathrm{K}$ da faixa hercínica tardia na Europa.

O diagrama triangular $\mathrm{Zr}-\mathrm{ASI} * 200$ - FMMT*30 (Figura 6) discrimina também os diferentes suítes de granitóides neoproterozóicos da região do Rio Doce. O valor FMMT corresponde ao $\mathrm{S}\left(\mathrm{FeO} *+\mathrm{MgO}+\mathrm{MnO}+\mathrm{TiO}_{2}\right)$ dos granitóides e assim aos seus minerais ferromagnesianos, essencialmente representados pela biotita, mineral comum em todos os granitóides da região e que contém até $80 \%$ de todos os cristais de zircão existentes nestas rochas. Em todas as Suítes granitóides, o valor desta soma diminui das fácies menos diferenciadas para as mais diferenciadas. Os minerais ferromagnesianos, em especial a biotita, parece controlar o comportamento do Zr durante a cristalização do magma. Além disso, o comportamento do Zr parece depender também dos valores de ASI nas diferentes Suítes granitóides(Pré-, Sín a Pós tectônico), aliás, de acordo com o trabalho experimental de Watson (1979) e Watson \& Harrison (1984) que mostraram que a solubilidade do zircão na fusão é fortemente controlada pelos valores de ASI. Os teores em $\mathrm{Zr}$ diminuem fortemente nos granitóides peraluminosos (Suíte Síntectônico) e moderadamente nos granitóides metaluminosos (Suíte Pré-tectônico). Nos granitóides Sín-tectônicos o zircão é um mineral de cristalização precoce, principalmente como incluso na biotita, causando assim uma proeminente redução dos teores de $\mathrm{Zr}$ na fusão residual.

Os teores em $\mathrm{Zr}$ aumentam nos Suítes granitóides Tardi a Pós-tectônicas até atingir a saturação em Zr na fusão, diminuindo nas partes mais diferenciadas dos corpos.

Os granitóides porfiríticos mostram a mesma tendência como a Suíte dos granitóides Pré-tectônicos, uma vez que apresenta uma evolução nos valores de ASI idêntica à estes (Figura 6).

No que se refere aos teores em ETR, parece que são sempre os mesmos fatores que determinam seus padrões de distribuição em todos os granitóides da região SE do Brasil. Os diagramas ${ }_{\mathrm{CN}}$ dos ETR mostram que os granitóides (Suítes) Tardi- a Pós-tectônicos têm teores mais elevados em ETR do que os granitóides (Suítes) Pré- e Sín-tectônicos.

Os aranhogramas ${ }_{\mathrm{ORG}}$, normalizados para a composição dos granitos do dorsais oceânicos (Pearce et al. 1984), mostram alto enriquecimento em Ba para todos os tipos dos granitos estudados (Figura 7). Este

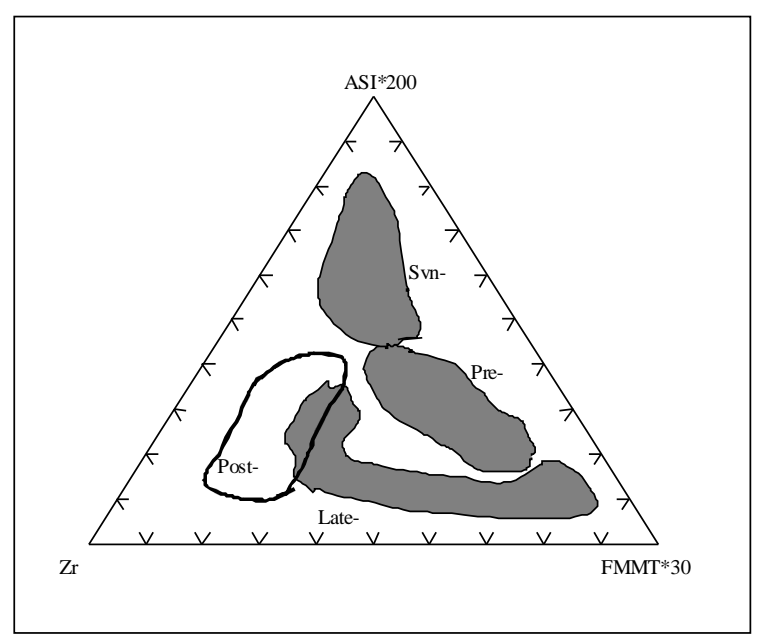

Figura 6: Os granitos Neoproterozóicos da região sudeste no diagrama $\mathrm{Zr}$-ASI*200-FMMT*30. Os

símbolos são os mesmos do que na figura 2.

Figure 6: Neoproterozoic granitoids of the southeastern Region plotted in the Zr-ASI*200-FMMT*30 diagram. For symbols look figure 2.

enriquecimento em Ba é muito nítido nos granitóides Tardi- a Pós-tectônicos, que são igualmente distinguidos por enriquecimento em Ke Rb. Nos granitóides dos Suítes Tardi-tectônicos (granitos hiperstênicos e porfiríticos) verificou-se um enriquecimento de $\mathrm{K}, \mathrm{Rb}$ e $\mathrm{Ba}$ relativamente ao Th. Os seus aranhogramas são semelhantes aos dos granitos de Vedrette di Ries (Alpes italianos).

Estes últimos granitóides contrastam claramente dos granitóides Pós-tectônicos em que o teor em Th ultrapassa os de $\mathrm{K}, \mathrm{Rb}$ e $\mathrm{Ba}$.

O aranhograma ${ }_{\mathrm{ORG}}$ dos granitóides Pós-tectônicos é ainda marcado por anomalias nos teores em $\mathrm{Th}, \mathrm{Ce}$ e Sm, do tipo do observado nos granitos do Complexo Sabaloka no Sudão caracterizados por elevada contaminação crustal.

Os granitóides Sín-tectônicos da região do Rio Doce apresentam um aranhograma semelhante ao dos granitos de Gabug (Tibete) e de Yunnan (SW da China) gerados por colisão continental da faixa móvel do Himalaia. Deste modo o enriquecimento nos teores em $\mathrm{Rb}, \mathrm{Ba}, \mathrm{Th}, \mathrm{Ce}$ e Sm nos granitóides estudados pode ser atribuído à contribuição do material crustal em sua gênese.

\section{IMPLICAÇÕES TECTÔNICAS}

Os granitóides (Suíte) Pré-tectônicos "Tonalito Galiléia" cristalizaram há 595Ma sob condições de alta pressão $(8-10 \mathrm{Kbar})$ e alta temperatura $\left(750^{\circ} \mathrm{C}-850^{\circ} \mathrm{C}\right)$. A presença da labradorita e de granada rica em grossulária nestes granitóides, a existência de duas populações de zircões, e de enclaves máficos, o elevado valor da razão inicial ${ }^{87} \mathrm{Sr}{ }^{\beta 6} \mathrm{Sr}(0,712-0,713)$ e o valor negativo de $\varepsilon \mathrm{Nd}_{(600 \mathrm{Ma})}(\mathrm{de}-8,9 \mathrm{a}-9,3)$ sugerem uma importante interação de magmas máficos, oriundos do manto superior, com material fundido de origem crustal (Nalini et al. 2000). 

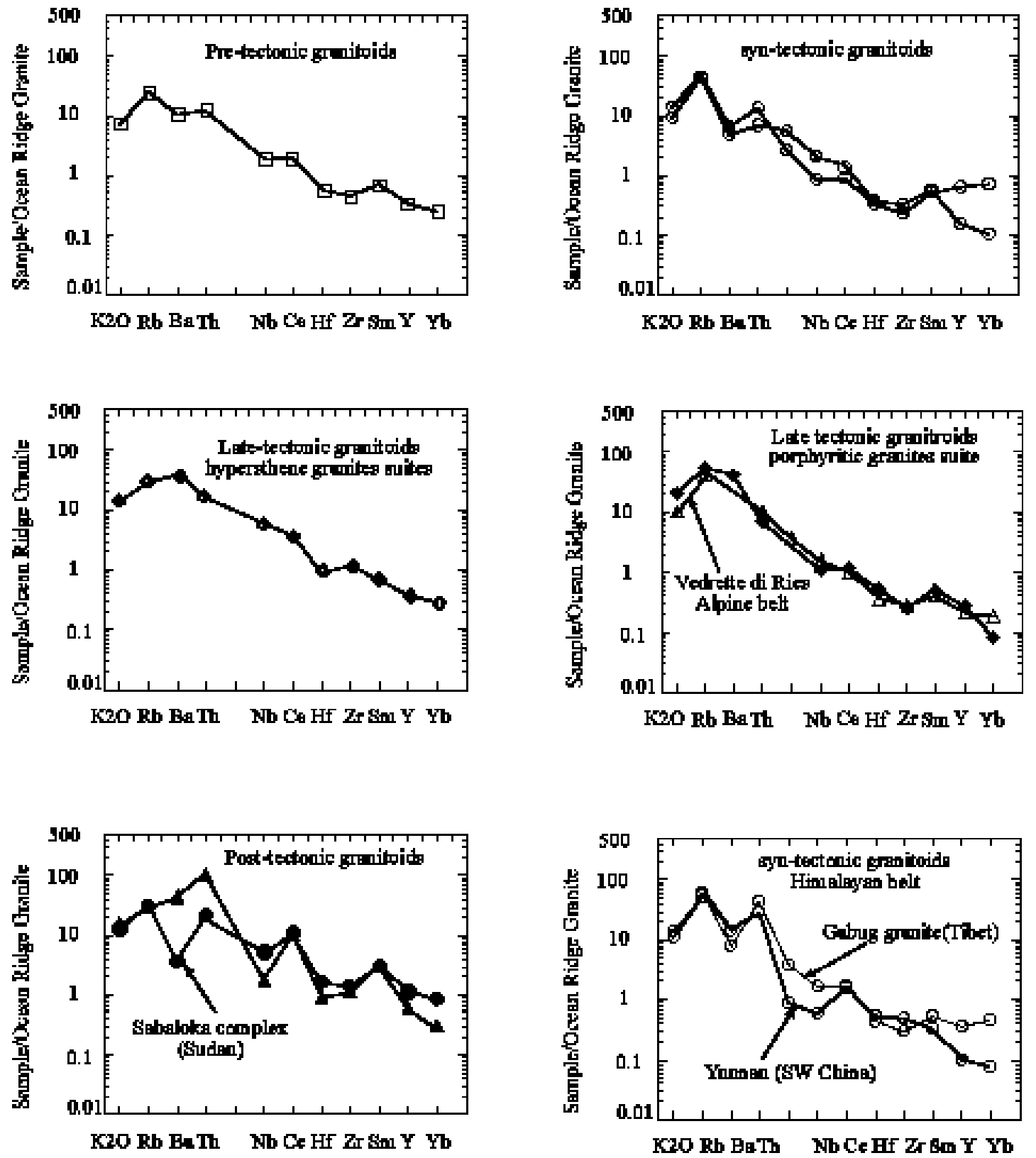

Figura 7: Aranhogramas dos suítes da região Rio Doce em comparação com granitos de origem crustal. Os símbolos são os mesmos do que na figura 2.

Figure 7: Spidergrams of the rocksuites of the granitoids from Rio Doce region in comparison with some well defined granites of crustal origin. For symbols look figure 2.

Estes granitóides foram exumados para uma profundidade correspondente a $4 \mathrm{Kbars}$ (cerca de $14 \mathrm{~km}$ ) e a $700^{\circ} \mathrm{C}$ durante a deformação principal $\mathrm{D}_{1}$ correspondente ao evento de colisão continental (Figura 8). A velocidade de exumação destes granitóides prétectônicos pode estimar-se em até no máximo de $2 \mathrm{~mm} /$ ano. A preservação da composição inicial dos anfibólios, da labradorita e da granada rica em grossulária mostra que a velocidade de exumação foi relativamente rápida. No decurso da descompressão (alívio da pressão litostática), causada pela rápida erosão, os metassedimentos paleoproterozóicos foram levados para o campo do líquidus e sofreram fusão parcial originando os leucogranitos sintectônicos
Urucum (com idade de 582Ma) e um primeiro grupo de pegmatitos portadores de elementos raros (PG1).

Este evento metamórfico-tectônico, bem caracterizado na região, foi datado entre 590-565Ma por Söllner et al. (1991) e por Machado et al. (1996). Estudos recentes demonstraram a importante contribuição da crosta paleoproterozóica destes granitóides Pré- e Sín-tectônicos (Nalini et al. 1998b).

A segunda fase de deformação $\left(\mathrm{D}_{2}\right)$, correspondendo a um episódio de extensão, relacionado com forte reativação tectônica de zonas de cavalgamento e marcada pela exumação das rochas gnáissicas de alto grau adjacentes pertencentes aos Complexos Juiz de Fora e Paraíba do Sul. 
Os granitóides Tardi- a Pós-tectônicos dos Complexos Intrusivos Anelares Aimorés, Ibituba/Itapina e Várzea Alegre formaram-se durante este evento. A sua intrusão esteve relacionada a uma abertura com uma tectônica de cavalgamento e de falhas verticais, sendo contemporânea com a justaposição tectônica devido ao falhamento tipo "strike-slip". A direção da abertura relacionada com o posicionamento crustal dos plútons foi E-W no Complexo Ibituba-Itapina e WSW-ENE para o Complexo Aimorés. A razão inicial ${ }^{87} \mathrm{Sr} /{ }^{86} \mathrm{Sr}(0,723)$ e o valor negativo de $\varepsilon \mathrm{Nd}_{(500 \mathrm{Ma})}(\mathrm{de}-7 \mathrm{a}-8)$ dos plútons sugerem uma importante contribuição de material crustal transamazônico (Mello, 2000).

A segunda deformação, $D_{2}$ é acompanhada pelo desenvolvimento de um pequeno volume de magma devido a uma segunda fusão parcial da qual resultaram quer os granitóides porfiríticos, quer um segundo grupo de pegmatitos simples (PG2). As características geoquímicas e petrográficas destes granitóides porfiríticos, muito diferentes das dos granitóides Sín-tectônicos que tem uma composição tipicamente crustal, implica um protólito diferente para a origem do seu magma provavelmente representado pelas rochas ortognaissicas de alto grau.

O fim do episódio de extensão crustal é caracterizado pelo posicionamento de granitóides pós-tectônicos do tipo que afloram no Maciço de Ibituruna. A presença de enclaves máficos a ultramáficos nos sienitos e nos granitos alcalinos do Complexo de Ibituruna implica uma contribuição de origem mantélica. Isto indica que as falhas do tipo "strike-slip", de idade pós-brasiliana, tiveram uma abrangência à escala da litosfera, permitindo que fusões mantélicas atingissem mesmo a crosta superior.

O mesmo modelo tectônico foi postulado se baseando em observações no setor sul e central da Faixa Ribeira (Costa et al. 1998; Fischer et al. 1998; Ebert et al. 1996 e Ebert \& Hasui 1998).

A existência de litosfera oceânica neoproterozóica foi caracterizada na Faixa Araçuaí (e.g., Pedrosa-Soares \& Wiedemann-Leonardos, 2000).

As características da atividade magmática, o arcabouço tectônico e a importante contribuição da crosta arqueana e paleoproterozóica na gênese da $\mathrm{s}$ diversas suítes granitóides (pré- a pós-tectônico)

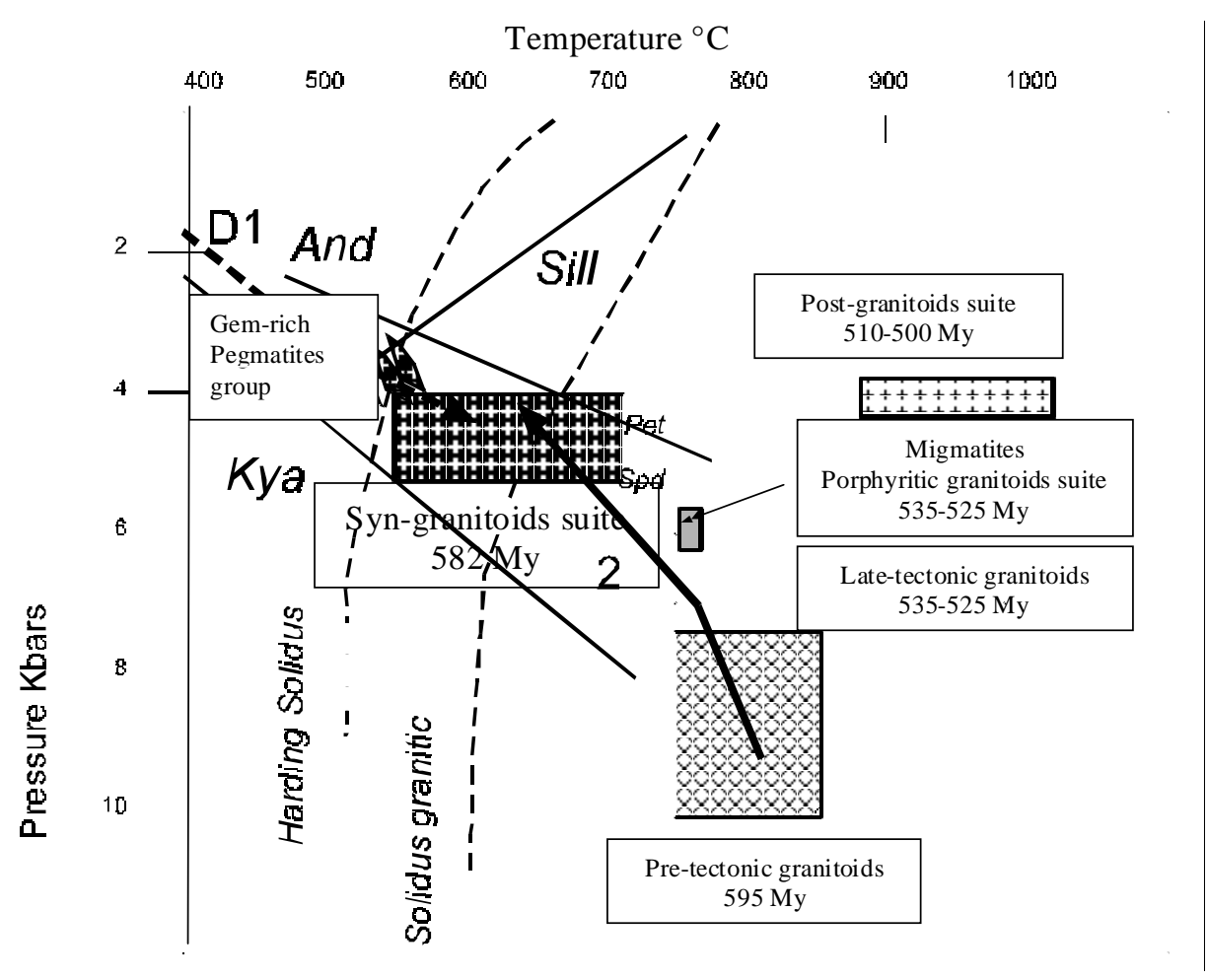

Figura 8: Compilação dos dados p-T-t dos granitóides neoproterozóicos da região Rio Doce. Os granitóides Pré-tectônicos foram exumados (2) durante a fase principal de deformação (D1; 590-565 Ma). Esta fase foi um evento colisional. Os granitos Sín-tectônicos e os pegmatitos I, rico em elementos raros, têm uma idade de \pm 582

Ma. Os granitos Tarde a Pós-tectônico e os pegmatitos II, ricos em elementos raros (537-520 Ma), são contemporâneos com a segunda fase da deformação D2 que corresponde a movimentos extencionais. Os granitos Pós-tectônicos posicionaram-se na crosta superior entre 511 a $500 \mathrm{Ma}$.

Figure 8: Compilation of the P-T-t Neoproterozoic granitoids of the Rio Doce Region. The pre-tectonic granitoids (595 My) are exhumed (2) during a main deformation phase D1 (590-565 My) corresponding to a collisional event. The syn-tectonic and the rare elements-rich pegmatites have an age of $\pm 582 M y$. The late and post-tectonic granitoids and the rare elements-rich pegmatites II (537-520My) are contemporaneous with the second phase of deformation D2 that corresponds to extensional movements. The post-tectonic granitoids were emplaced in the upper crust, 511 to $500 \mathrm{Ma}$. 
implicam um modelo de colisão continental na parte Centro Norte da Província Estrutural Mantiqueira. Muitos estudos realizados na parte sul da Faixa Ribeira (Wernick 1990; Ebert et al. 1996) suportam o mesmo modelo de colisão continental.

\section{CONCLUSÕES}

As conclusões mais importantes que nossas pesquisas evidenciaram na região do Rio Doce são: (1) as características petrológicas das diversas suítes granitóides da região do Rio Doce estão intimamente relacionadas com o enquadramento tectônico;

(2) o plutonismo na região do Rio Doce abrangeu um intervalo de tempo de cerca de $100 \mathrm{Ma}$, entre 595Ma e 490Ma;

(3) continuam sendo necessários trabalhos pormenorizados de cartografia geológica, de petrografia, de geoquímica e geocronologia para esclarecer os problemas ainda pendentes para a compreensão da gênese dos suítes granitóides da parte Central da Província Estrutural Mantiqueira. Como até o presente momento evidências conclusivas da existência de crosta oceânica não foram encontradas na porção central e sul da Província Estrutural Mantiqueira, tendo sido somente descritas para a parte norte da província (e.g. Pedrosa-Soares \& WiedemannLeonardos, 2000), o modelo mais adequado para explicar a origem dos granitóides das partes centrais e sul da Província Estrutural Mantiqueira é o da colisão continental.

\section{AGRADECIMENTOS}

Este trabalho é o resultado de uma colaboração internacional entre universidades da França (Ecole des Mines de St. Etienne; Université Jean Monnet) e do Brasil (Universidade Federal de Minas Gerais; Universidade Federal de Ouro Preto).

Agradecemos aos seguintes instituições: CNPq, CAPES, FAPEMIG, CNEN/CDTN, CNRS, e COFECUB.

Agradecemos também ao colega Dr. Francisco Javier Rios pela ajuda com os desenhos e aos revisores pelas sugestões valiosas.

\section{REFERÊNCIAS BIBLIOGRÁFICAS}

Bilal E. \& Correia Neves J.M. 1997. Neoproterozoic Ibituruna syenite complex (Minas Gerais state, Brazil). In: International Symposium on Granites and Associated Mineralizations, ISGAM, 2, Salvador, Excursions guides book: 119-120.

Bilal E., Nalini H.A., Horn, A.H., Correia-Neves, J.M., Giret, A.R., Fuzikawa, K., Fernandes, M.L.S., Mello, F., Moutte, J. 1998. Neoproterozoic granitoid suites of Rio Doce Region, Brazil. In: International Conference on Precambrian and Craton Tectonics, Ouro Preto. Extended Abstracts: 41-43.

Bilal E., Horn, A.H., Nalini H.A., Mello m. de F., Correia-Neves, J.M., Giret, A.R., Moutte, J., Fuzikawa, K. \& Fernandes, M.L.S. 2000a. Neoproterozoic granitoid suites in southeastern Brazil. Rev. Bras. Geol. V 30: 1/2/3: CD
Bilal E., Correia-Neves, J.M., Fuzikawa, K., Horn, A.H., Marciano, V.R. da R.O., Fernandes, M.L.S., Mello, F.M. de, Moutte, J. \& Nasraoui, M. 2000b. Pegmatites of southeastern Brazil. Rev. Bras. Geol. V 30, 1/2/3: CD.

Blundy, J.D. \& Holland, T.J. 1990. Calcic amphibole equilibria and a new amphibole-plagioclase geothermometer. Contributions to Mineralogy and Petrology, 104: 208-224.

Bowden, P., Batchelor, R.A., Chappell, B.W., Didier, J. \& Lameyre, J. 1984. Petrological geochemical and source criteria for the classification of granitic rocks : a discussion. Physics of the Earth and Planetary Interiors, 35: 1-11.

Campos-Neto M.C. \& Figueiredo, M.C.H. 1995. The Rio Doce orogeny, southeastern Brazil. Journal of South American Earth Sciences, 8(2):143-162.

Chemenda, A., Mattauer, M., Malavieille, J. \& Bokun, A., 1995. A mechanism for syn-collisional rock exhumation and associated normal faulting : results from physical modelling. Earth Planet. Sci. Lett. 132: 225-232.

Correia Neves, J.M., Pedrosa-Soares, A.C. \& Marciano, V.R. 1986. A Provincia Pegmatitica oriental do Brasil à luz dos conhecimentos atuais. Rev. Bras. Geociências, 16: 106-118.

Costa, A.G., Rosière, C.A., Ebert, H.D., Fischel, D.P., Fuck, R.A. \& Pimentel, M.M. 1998. The relation between frontal and strikeslip shear zones and the regional metamorphism and magmatism in a deep-crustal Conference on Precambrian and Craton Tectonics, Ouro-Preto: 26-28.

De la Roche, H., Leterrier, J., Grandclaude, P. and Marchal, M. 1980. A classification of volcanic and plutonic rocks using R1R2 diagram and major element analyses. Its relationships with current nomenclature. Chemical Geology, 29: 183-210.

Ebert, H.D. and Hasui, Y. 1998. Transpressional tectonic and strain partitioning during oblique collision between three plates in the precambrian of south-east Brazil. In Holdsworth, R.E., Strachan, R.A., Dewey, J.F. (ed) Continantal Transpressional/Transtensional Tectonics. Geological Society, London, Special Publications (Blackwell), 135: 231-252.

Ebert H.D., Chemale F., Babinski M., Artur A.C. \& Van Schmus W.R. 1996. Tectonic setting and U/Pb zircon dating of the plutonic Socorro Complex in the Transpressive Rio Paraiba do Sul Shear Belt, SE Brazil. Tectonics, 15(2):688-699.

Fischel, D.P., Pimental, M.M., Fuck, R.A., Costa, A.G. \& Rosiere., C.A. 1998. Geology and Sm-Nd isotopic data for the mantiqueira and Juiz de Fora complexes (Ribeira Belt) in the abre CampoMinhaçu region, Minas Gerais, Brazil. In International Conference on Precambrian and Craton Tectonics, Ouro-Preto: 21-23.

Horn A.H., Giret A.R., Bilal E., Correia-Neves J.M. \& Carvalho S 1996. O complexo intrusivo Ibituba-Itapina, noroeste do estado de Espírito Santo - resultados e caracterização preliminares. In: SBG, Congresso Brasileiro de Geologia, 39, Salvador, Anais, 6: 375-378.

Horn A.H., Giret A.R., Bilal E. \& Correia-Neves J.M. 1998. Der Ibituba-Itapina Intrusiv Komplex im Ribeira Mobile Belt, Espírito Santo, Brasilien. Lateinamerika Kolloquium, Bayreuth, Germany. Zusammensfassungen Heft: 56-57.

Machado N., Valadares C., Heilbron M. \& Valeriano C. 1996. U-Pb geochronology of the central Ribeira belt (Brazil) and implications for the evolution of the Brazilian Orogeny. Precambrian Research, 79: 347-361.

Mello, F.M. 2000. Lithogeoquimica e quimica mineral do maciço charnockitico Almoreis MG; Tese de doutoramento IG-USP, 217p.

Morteani, G., Preinfalk, C. \& Horn, A.H. 2000. Classification and mineralization potencial of the pegmatites in the Eastern Brazilian Pegmatite Province. . Mineralium Deposita 35: 638-655.

Nalini H.A. 1997. Caractérisation de suites magmatiques néoprotérozoïques de la région de Conselheiro Pena et Galiléia (Minas Gerais, Brésil). Ecole des Mines de Saint-Etienne, SaintEtienne, France, These de doutoramento: $321 \mathrm{p}$.

Nalini, H.A., Bilal, E. \& Correia-Neves, J.M. 2000. Syn-collisional peraluminous mamatism in the Rio Doce region: mineralogy, geochemistry and isotopic data for the Neoproterozoic Urucum Suite (eastern Minas Gerais State, Brazil). Rev. Bras. Geol. V 30, 1/2/3: CD. 
Nachit, H. 1986. Contribution à l'étude analytique et expérimentale des biotites des granitoïdes. Applications typologiques. Université de Bretagne Occidentale, Brest, These de doutoramento: 238 p.

Pearce, J.A., Harris, N.B.W. \& Tindle, A.D. 1984. Trace element discrimination diagrams for the tectonic interpretation of granite rocks. J. Petrol. 25/4: 956-983.

Pedrosa-Soares A.C., Wiedemann C.M., Fernandes M.L.S., Faria L.F. \& Ferreira J.C.H. 1999. Geotectonic significance of the Neoproterozoic granitic magmatism in the Araçuaí Belt: A model and pertinent questions Rev. Bras. Geoc. 29(1): 59-66.

Pedrosa-Soares, A.C. \& Wiedemann-Leonardos, C.M. 2000. Evolution of the Araçuaí Belt and its connections to the Ribeira Belt, eastern Brazil. In: Cordani, U.G., Milani, E.J., Thomaz Filho, A. \& Campos D.A. (eds), Tectonic Evolution of South America. Rio de Janeiro, 31 Intern. Geol. Cong., p. 231-264.

Pinto, C.P. 1997 (1977). Projeto Leste-MG. Relatório Integrado.CD

Pupin, J.P. 1980. Zircon and Granite Petrology. Contrib. Min. Petrol. 73: $207-220$.

Schmidt, M.W. 1992. Amphibole composition in tonalite as a function of pressure: an experimental calibration of the Al-inhornblende barometer. Contrib. to Min. Petrol., 110: 304-310
Söllner F., Lammerer B. \& Weber-Diefenbach K. 1991. Die Krustenentwicklung in der Küstenregion nördlich von Rio de Janeiro/Brasilien. Münchener Geologische Hefte, 4: 100 pp.

Watson, E.B. and Harrison, TM., 1984. Accessory minerals and geochemical evolution of crustal magmatic systems. A summary and prospectus of experimental approaches. Phys. Earth. Planet. Int., 35: 19-30.

Watson, E.B., 1979. Zircon saturation in felsic liquids: experimental results and applications to trace element geochemistry. Contrib. Min. Petrol., 70: 407-419.

Wells, P.R.A. 1977. Pyroxene thermometry in simple and complex systems. Contrib. Min. Petrol. V 62: 129-139.

Wernick E. 1990. Zoneamento magmático regional de granitóides brasilianos no sudeste/sul do Brasil : implicações geotectônicas. In: SBG, Congresso Brasileiro de Geologia, 36, Natal, Anais 4: 1668-1683.

Wiedemann C.M. 1993. The evolution of the early Palaeozoic, Lateto post-collisional magmatic arc of the Coastal Mobile Belt, in the state of Espírito Santos, eastern Brazil. Anais da Academia Brasileira de Ciências. 65: 163-181. 